\title{
A REVERSE HILBERT-LIKE OPTIMAL INEQUALITY
}

\section{OMRAN KOUBA}

Abstract. We prove an inequality on positive real numbers, that looks like a reverse to the wellknown Hilbert inequality, and we use some unusual techniques from Fourier analysis to prove that this inequality is optimal.

Mathematics subject classification (2010): 42A16, 42A38, 42B20.

Keywords and phrases: Inequalities, Fourier series, Fourier transform.

\section{REFERENCES}

[1] M. Abramowitz AND I. A. STEgan (Eds), Handbook of Mathematical Functions, with Formulas, Graphs, and Mathematical Tables, Dover Books on Mathematics, Dover Publication, Inc., New York (1972).

[2] P. P. DÁlyay, Proposed problem 11769, The American Mathematical Monthly, vol. 121 (4) (2014), p. 365, http://dx.doi.org/10.4169/amer.math.monthly.121.04.365.

[3] L. Debnath And B. YAng, Recent Developments of Hilbert-Type Discrete and Integral Inequalities with Applications, International Journal of Mathematics and Mathematical Sciences, vol. 2012, Article ID 871845 (2012), p. 29, http://dx.doi.org/10.1155/2012/871845.

[4] G. H. Hardy, J. E. LitTlewood And G. Pólya, Inequalities, Second edition, Cambridge University Press (1952).

[5] M. Krnić, J. Pečarić, I. Perić And P. Vuković, Recent Advances in Hilbert-type Inequalities, Element, Zagreb (2012), http://element.hr/artikli/514/recent-advances-in -hilbert-type-inequalities.

[6] J. Waldvogel, Towards a general error theory of the trapezoidal rule, Approximation and Computation. In honor of Gradimir V. Milovanović. W. Gautschi, G. Mastroianni, Th. M. Rassias (eds.), Springer Optimization and its Applications 42, Springer, New York, (2011), pp. 267-282, http://dx.doi.org/10.1007/978-1-4419-6594-3_17.

[7] E. W. Weisstein, Gamma Function, From MathWorld - A Wolfram Web Resource, http://mathworld. wolfram. com/GammaFunction.html.

[8] B. YANG, Discrete Hilbert-Type Inequalities, Bentham Science Publishers (2011). 